\title{
Developing an AR-Based Upper Limb Rehabilitation System with Sensors
}

\author{
Qiang Wang ${ }^{1, \text { a }}$, Xiao Li , Lu Zeng $^{\text {2,b }}$ and Qinghao Cao ${ }^{3, \mathrm{c}}$ \\ 1, *, 2, 3 School of Computer and Information Science, Southwest University \\ Chongqing, China \\ a wqwq1219@163.com, "lixiaoatswu@139.com, ’ yujiezeng@163.com, 18183079914@163.com
}

Keywords: Augmented reality, Upper Limb Rehabilitation, Architecture, Sensors.

Abstract. The upper-limb rehabilitation and training process with virtual reality-based systems makes patients anxious to some extent. Augmented reality (AR) technology works by enhancing one's current perception of reality, overlaying the computer-generated coaching information on the real exercise environment, which shows the patient the steps in clear and correct way. Beginning with a comparative analysis of existing systems' four aspects including goal descriptions, training parts, effect evaluation methods, and technical features, this paper also particularly discusses the key tracking and registration technology in depth. Then focusing on the tracking and locating of upper limb movement and evaluation of rehabilitation effects, a new architecture of the AR-based system with sensors is launched. The system mainly consists of four components: real training scene, virtual training scene, the human-computer interaction and the generation and display of virtual-reality fusion scene. The system's workflow is discussed as well. What' more, the effect of rehabilitation on the upper-limb movement disorders can be realized by analyzing the motion data and virtual-reality fusion scene.

\section{Introduction}

Upper limb is a part of the human body, which plays an important role for daily life activities ${ }^{[1]}$. However, upper limb movement disorders become more common with the frequency of various diseases or accidents. The symptoms of movement disorders are: limited range of motion, slow movements and uncontrolled trembles ${ }^{[2]}$. Nowadays, one of training methods for rehabilitation is the use of virtual computer systems like Biomaster that can't monitor and evaluate the recovery process ${ }^{[3]}$. What's more, facing the completely virtual world, it is impossible for patients to feel the pleasure of improvements.

AR is short for Augmented Reality technology, which fuses the real environment with the virtual information generated by computer to enhance the real world ${ }^{[4]}$. The system that utilize AR technology constructs a virtual-reality fusion training environment to make patients keep in touch with the real world, which is helpful to improve the rehabilitation better. At present, the key technologies for applying AR to rehabilitation systems include the modeling of 3D scenes, the tracking and registration of 3D environments, the display of virtual-reality fusion and human-computer interaction.

In the training process, the motion data acquisition, the tracking of upper limb movements and the evaluation of rehabilitation effects are the key problems that need to study further. For these problems, this paper proposes a new solution of the AR-based system with sensors.

The rest of this paper is organized as follows. Section II introduces related work and particularly analyzes the implementation methods of key tracking and registration technology. Section III suggests a new AR-based system architecture with sensors and presents the system's workflow. The conclusion section discusses the work for the future as well.

\section{Related Work}

In the field of AR-based upper limb rehabilitation system, foreign researches are earlier than China, which centers on USA, Australia and England. And some preliminary research productions have been 
found. Researches in China are still in the early stage of laboratory research at present.

The following Table I enumerates some of present AR-based rehabilitation systems with a comparative analysis of these systems' four aspects that include goal description, training parts, effect evaluation methods and technical features.

Table I The comparisons of the existing AR-based upper limb rehabilitation systems

\begin{tabular}{|c|c|c|c|c|c|}
\hline No. & Title or System & Goal & $\begin{array}{l}\text { Training } \\
\text { Parts }\end{array}$ & $\begin{array}{c}\text { Effect Evaluation } \\
\text { Methods }\end{array}$ & Technical Features \\
\hline 1 & $\begin{array}{l}\text { Integration } \\
\text { augmented reality and } \\
\text { assistive devices for } \\
\text { post-stroke hand } \\
\text { opening rehabilitation }{ }^{[5]} \\
(2005)\end{array}$ & $\begin{array}{l}\text { The head mounted display } \\
\text { and assistive device are } \\
\text { used to train the fingers for } \\
\text { post-stroker hand } \\
\text { rehabilitation }\end{array}$ & Fingers & $\begin{array}{l}\text { Measure auxiliary force } \\
\text { provided by the } \\
\text { assistive device to } \\
\text { evaluate training } \\
\text { effects. }\end{array}$ & $\begin{array}{l}\text { A head mounted display is used for } \\
\text { 3D objects visualization. An } \\
\text { assistive device is used to control } \\
\text { fingers stretching }\end{array}$ \\
\hline 2 & $\begin{array}{l}\text { Computer Assisted } \\
\text { Music Therapy: a Case } \\
\text { Study of an Augmented } \\
\text { Reality Musical System } \\
\text { for Children } \quad \text { with } \\
\begin{array}{lr}\text { Cerebral } & \text { Palsy } \\
\text { Rehabilitation }^{[6]} & (2009) \\
\end{array}\end{array}$ & $\begin{array}{l}\text { The computer assisted } \\
\text { music therapy is used to } \\
\text { help children with cerebral } \\
\text { palsy do vision and hearing } \\
\text { training and upper limb } \\
\text { training to recover motion } \\
\text { function. }\end{array}$ & $\begin{array}{l}\text { Fingers, } \\
\text { shoulder, } \\
\text { wrist }\end{array}$ & $\begin{array}{l}\text { Subjective evaluations: } \\
\text { the stretch of fingers } \\
\text { and the flexibility of the } \\
\text { wrist }\end{array}$ & $\begin{array}{l}\text { the different positions of mark cards; } \\
\text { the different organization forms of } \\
\text { mark cards }\end{array}$ \\
\hline 3 & $\begin{array}{l}\text { Augmented Reality } \\
\text { Games for Upper -limb } \\
\text { Stroke Rehabilitation }{ }^{[7]} \\
(2010)\end{array}$ & $\begin{array}{l}\text { By means of Brick'a'Break } \\
\text { and ShelfStack to improve } \\
\text { the flexion-extension of the } \\
\text { fingers and elbow }\end{array}$ & $\begin{array}{l}\text { Wrist, } \\
\text { elbow, } \\
\text { fingers }\end{array}$ & $\begin{array}{l}\text { The time to fulfill tasks } \\
\text { and the score obtained } \\
\text { within the fixed time } \\
\text { are as indexes to } \\
\text { evaluate training effects }\end{array}$ & $\begin{array}{l}\text { Two games are designed to make } \\
\text { rehabilitation training interesting; } \\
\text { the real different shape and weights } \\
\text { objects with marks attached are } \\
\text { used. }\end{array}$ \\
\hline 4 & $\begin{array}{l}\text { AR based Upper Limb } \\
\text { Rehabilitation System }{ }^{[8]} \\
\text { (2012) }\end{array}$ & $\begin{array}{l}\text { Different training programs } \\
\text { are designed for different } \\
\text { training parts. By } \\
\text { completing different tasks } \\
\text { to train the joints of upper } \\
\text { limb, which helps patients } \\
\text { recover motor function. }\end{array}$ & $\begin{array}{l}\text { Wrist, } \\
\text { elbow }\end{array}$ & $\begin{array}{l}\text { The time to complete } \\
\text { tasks and the score of } \\
\text { the task are used to } \\
\text { estimate effects }\end{array}$ & $\begin{array}{l}\text { Color objects are used as AR marks. } \\
\text { The system consists of two modules: } \\
\text { AR based rehabilitation exercise } \\
\text { module and real-time active muscle } \\
\text { module }\end{array}$ \\
\hline 5 & $\begin{array}{l}\text { A spatial } \quad \text { augmented } \\
\text { reality rehab system for } \\
\text { post-stroker } r \quad \text { hand } \\
\text { rehabilitation }^{[9] \quad(2013)}\end{array}$ & $\begin{array}{l}\text { Virtual objects and } \\
\text { real-world objects are } \\
\text { operated to train the rotation } \\
\text { of the wrist and the } \\
\text { flexion-extension of fingers. }\end{array}$ & $\begin{array}{l}\text { Fingers, } \\
\text { wrist, } \\
\text { shoulder }\end{array}$ & $\begin{array}{l}\text { By measuring the } \\
\text { movement range, rate } \\
\text { and smooth degree of } \\
\text { hand to evaluate the } \\
\text { effect of rehabilitation } \\
\text { training. }\end{array}$ & $\begin{array}{l}\text { A projector is used as the display } \\
\text { equipment. Holding and tilting a real } \\
\text { mug to gradually pour virtual water }\end{array}$ \\
\hline 6 & 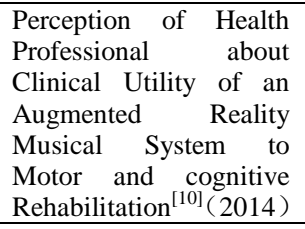 & $\begin{array}{l}\text { Augmented Reality Musical } \\
\text { System is used to } \\
\text { distinguish different sounds } \\
\text { and operate mark cards to } \\
\text { recover motor function and } \\
\text { cognitive ability. }\end{array}$ & $\begin{array}{l}\text { Wrist, } \\
\text { elbow, } \\
\text { shoulder }\end{array}$ & $\begin{array}{l}\text { The time required to } \\
\text { complete specific tasks } \\
\text { as evaluation index of } \\
\text { training effects }\end{array}$ & $\begin{array}{l}\text { The combination of vision and } \\
\text { hearing. The feedback of vision can } \\
\text { be generated from manipulating } \\
\text { color cards. }\end{array}$ \\
\hline 7 & $\begin{array}{l}\text { The Research of } \\
\text { Training Rehabilitation } \\
\text { system based on } \\
\text { Augmented Reality } \\
\text { (2012) }\end{array}$ & $\begin{array}{l}\text { A rehabilitation system is } \\
\text { designed to train the } \\
\text { movement flexibility of } \\
\text { hand for recovering the } \\
\text { motion function of hand. }\end{array}$ & $\begin{array}{l}\text { Wrist, } \\
\text { fingers }\end{array}$ & $\begin{array}{l}\text { The calculation and } \\
\text { comparison of final } \\
\text { scores is used to } \\
\text { evaluate the training } \\
\text { effect. }\end{array}$ & $\begin{array}{l}\text { The random appearance of the } \\
\text { virtual objects and the recognition of } \\
\text { static hand gestures }\end{array}$ \\
\hline
\end{tabular}

From the Table I, it can be seen that these systems have strong pertinences. Generally speaking, a system is aimed at a certain joint or several joints to train. Perhaps a system is direct at fingers or elbows and wrists. As the key technology of these systems, the Mark-based computer vision algorithms are used to track movements, which implement the locating of the upper limb. The following Table II discusses the key tracking and registration technology in particular. 
Table II The analysis of tracking and registration technology

\begin{tabular}{|c|c|c|c|}
\hline No. & Title or System & & Implementations of the key tracking and registration technology \\
\hline 1 & $\begin{array}{l}\text { Integration of augmented reality and } \\
\text { assistive devices for post-stroke hand } \\
\text { opening rehabilitation }^{[5]}(2005)\end{array}$ & $\begin{array}{l}(1) \\
(2)\end{array}$ & $\begin{array}{l}\text { Ascension Flock of Birds is used to track the hand. } \\
\text { VRCO is utilized to read the positions and orientations of the hand. }\end{array}$ \\
\hline 2 & $\begin{array}{l}\text { Computer Assisted Music Therapy: a } \\
\text { Case Study of an Augmented Reality } \\
\text { Musical System for Children with } \\
\text { Cerebral Palsy Rehabilitation }{ }^{[6]} \\
\text { (2009) }\end{array}$ & (1) & $\begin{array}{l}\text { Make use of color cards as the stationary marks. When a card is occluded in position, } \\
\text { webcam will track the hand's position. } \\
\text { Image Processing Technology is used to recognize the card s and judge the } \\
\text { occlusions. }\end{array}$ \\
\hline 3 & $\begin{array}{l}\text { Augmented Reality Games for Upper } \\
\text {-limb Stroke Rehabilitation }{ }^{[7]} \\
(2010)\end{array}$ & (1) & $\begin{array}{l}\text { Combing with AR tracking algorithms and ARToolKitPlus library, the fixed webcam } \\
\text { is used to track the real objects with AR marks attached } \\
\text { The move of real objects is controlled by hand and the position of the virtual objects } \\
\text { is calculated, which achieves the tracking of the hand movements. }\end{array}$ \\
\hline 4 & $\begin{array}{l}\text { AR based Upper Limb Rehabilitation } \\
\text { System }^{[8]}(2012)\end{array}$ & $\begin{array}{l}\text { (1) } \\
\text { (2) } \\
\text { (3) }\end{array}$ & $\begin{array}{l}\text { The computer vision algorithms are used to track the arm and the wrist with color } \\
\text { marks attached } \\
\text { The tracking of color marker is used based on 24-bit RGB true color space. } \\
\text { Collision detection of the marker and virtual interactive objects were done by } \\
\text { checking the distance value of center points of marker and virtual interactive object. }\end{array}$ \\
\hline 5 & $\begin{array}{l}\text { A spatial augmented reality rehab } \\
\text { system for post-stroke hand } \\
\text { rehabilitation }{ }^{[9]}(2013)\end{array}$ & $\begin{array}{l}(1) \\
(2) \\
(3)\end{array}$ & $\begin{array}{l}\text { The virtual objects are projected on a table by a projector. The webcam is fixed. } \\
\text { The color marks are attached to fingers and the opisthenar to complete different } \\
\text { tasks. } \\
\text { By means of different computer vision algorithms to track positions of color cards, } \\
\text { which achieves the tracking of different parts of the hand. }\end{array}$ \\
\hline 6 & $\begin{array}{l}\text { Perception of Health Professional } \\
\text { about Clinical Utility of an } \\
\text { Augmented Reality Musical } \\
\text { System to Motor and cognitive } \\
\text { Rehabilitation }{ }^{[10]} \text { (2014) }\end{array}$ & $\begin{array}{l}(1) \\
(2)\end{array}$ & $\begin{array}{l}\text { The webcam makes use of image processing technology to track the fixed marks. } \\
\text { The position of the mark will be captured and judged after the mark is touched, } \\
\text { which confirms the position of the fingers. }\end{array}$ \\
\hline 7 & $\begin{array}{l}\text { The Research of Training } \\
\text { Rehabilitation system based on } \\
\left.\text { Augmented Reality }{ }^{[11]} 2012\right)\end{array}$ & $\begin{array}{l}\text { (1) } \\
(2) \\
(3)\end{array}$ & $\begin{array}{l}\text { Make use of Artoolkit and OpenCV library to capture and process every frame of the } \\
\text { image in the real world. } \\
\text { The webcam can be placed in different positions and the cards with marks attached } \\
\text { can be moved randomly. } \\
\text { The tracking and recognization of the hand is realized via moving the cards. }\end{array}$ \\
\hline
\end{tabular}

The AR markers and computer vision algorithms can be used to track upper limb movements, which can't get the related data of the movements. So the effect of rehabilitation can't be evaluated quantitatively. However, sensors are the devices that can effectively collect the motion data ${ }^{[12]}$. Now with the development and application of wearable devices, the sensor technology has been widely used. Thus, this paper proposes a new architecture of AR-based rehabilitation system that utilizes sensors to complete the tracking and data acquisitions.

\section{Design scheme for AR-based upper limb rehabilitation system with sensors}

Design Idea. Sensors are detection devices that can monitor the data and transform it into other required forms in order to achieve the transmission, processing, storage and display ${ }^{[12]}$. In the proposed system, the sensor is mainly used to track the upper limb and collect the motion data, such as angles and orientations. And the data plays an important role for the patients' rehabilitation. On the one hand, this data can reflect the upper limb movements. The analysis of this data will measure the training performance. On the other hand, the changes of range of motion and flexibility can be seen through the comparison of these different trainings data, which will appraise patients' recovery.

These existing systems just make use of AR technology to provide a training platform for patients without any scientific and reasonable method to evaluating training effects. The use of sensors can solve the problem exactly, which makes AR technology get used better. Meanwhile, the utilizing of AR technology creates many favorable conditions for the combination of sensors, which makes the sensors have a key role to play. The combination of AR technology and sensors makes the system more humanized and more complete.

System Architecture. The system is designed to be able to evaluate the training in real time and then immediately reflect this evaluation in the training, which consists of real training scene, virtual training scene, the human-computer interaction and the generation and display of virtual-reality fusion scene, as shown in Fig.1.

The real training scene refers to a realistic workspace, where the trainings will be conducted actively and independently. The range of motion, flexibility and coordination of upper limb will be improved 
by doing the exercises repeatedly. The virtual training scene is a computer-generated training platform, where a virtual object will move following the movements to simulate the upper limb. The generation and display of virtual-reality fusion scenes is a module that can generate and present the fusion of virtual scenes and real scenes, which accomplishes the synchronization of the virtual object and the real upper limb with the tracked position information and presents the motion data in the screen in real time. The human-computer interaction is a medium that transmits data and information between patients and the system, in which the sensor is used as a key equipment to track the movements and collect the motion data.

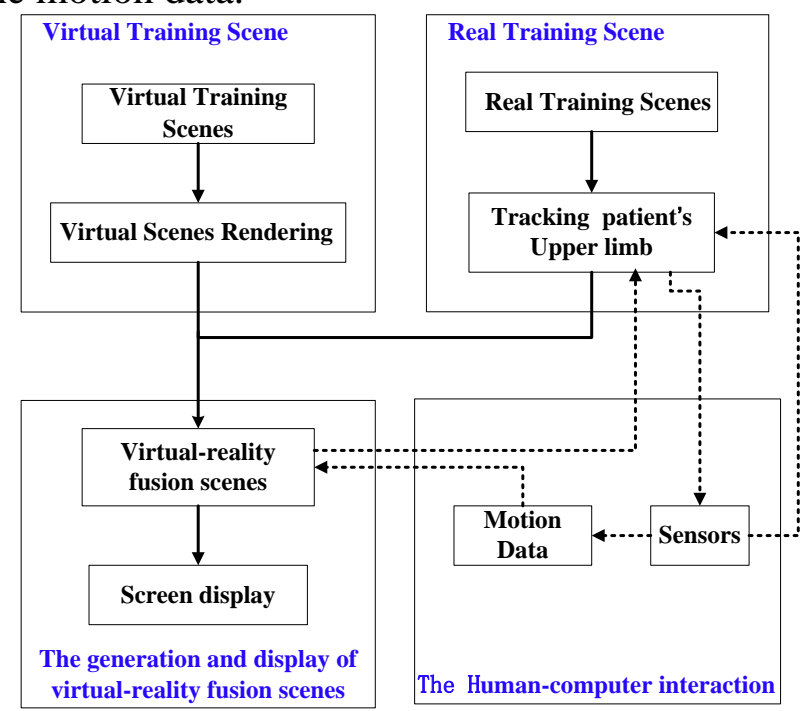

Fig.1 The architecture of AR-based upper limb rehabilitation system with sensors

These modules are closely related, which perform these trainings together. The concurrent construction of virtual scenes and real scenes ensures the generation and display of virtual-reality fusion scenes. The cooperation of the human-computer interaction and real scenes implements the accurate tracking and data acquisition. And the combination of the human-computer interaction and the generation and display of virtual-reality fusion scenes guarantees the real-time transmission and show of the motion data. The system's workflow will be presented next. 


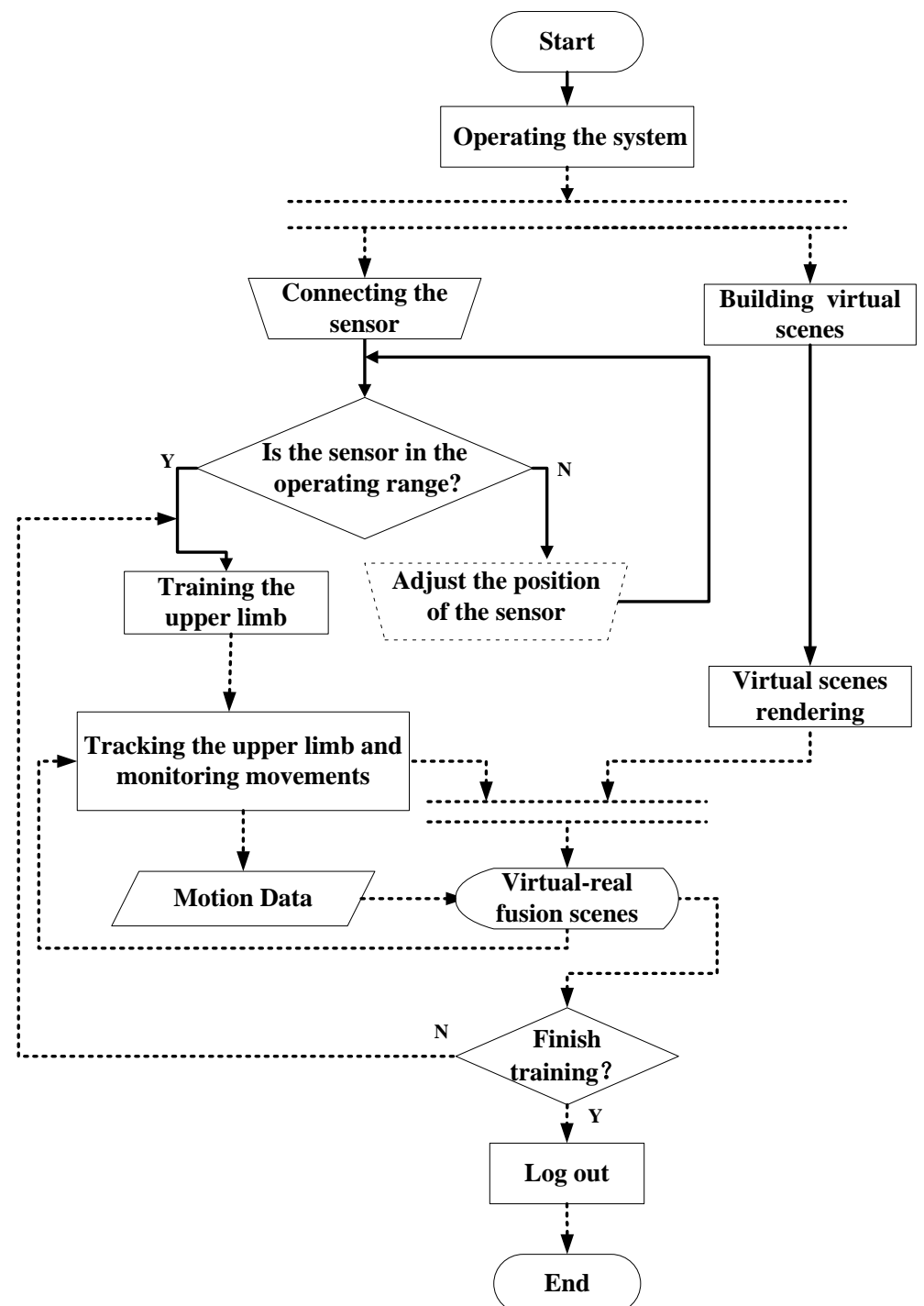

Fig.2 The work flowchart of AR-based upper limb rehabilitation system with sensors

System Process. Fig. 2 presents a work flowchart of the system from the data-driven perspective. The motion data is collected by sensors to monitor the training and evaluate the rehabilitation effect. The transmission of the motion data makes patients interact with the system in the workflow. Meanwhile, the circulation of the motion data makes the combination of these different parts possible. Thus, the motion data is the mainline of the workflow, which will be shown directly in screen.

Patients will get to know the movements by observing the data. That the observed value is same or similar with normal value means that the movements are normative. Then patients can continue doing this training. The large difference between observed value and normal value indicates that the actions are not normative. And then patients must timely adjust to make these movements normative again. This way can ensure that every movement is normative as far as possible. In addition, the changes of range of motion and flexibility can be found by comparing the different training data, which can evaluate the effect of rehabilitation.

\section{Conclusions and Future Work}

By deep analyzing existing AR-based upper limb rehabilitation systems, it can be found that webcams and computer vision algorithms are applied to track and recognize the AR marks attached to the upper limb, which tracks the movements indirectly. Furthermore, the training effect is evaluated only by subjectively observing the completion of tasks and the time to fulfill the tasks, which is not scientific without accurate related motion data. Focusing on the problem, this paper proposes a new architecture of AR-based upper limb rehabilitation system with sensors. The sensor is used to acquire the motion 
data such as time, angle and orientation. The analysis of the data is able to track the upper limb and evaluate the effect of rehabilitation effectively combing with a training plan.

The current work is a primary achievement. Next a system prototype based on this architecture will be designed for the shoulders' rehabilitation. The user (patients) testing method will be used to evaluate the prototype's clinical usability and efficiency. Combing with the daily training of rehabilitation department, six or eight patients will be chosen to use the prototype to do the training under the supervision and guidance of a therapist.

\section{References}

[1] (In Chinese) Fengying Shi, Rehabilitation Nursing, Second ed., People's Medical Publishing House, Beijing, 2006.

[2] (In Chinese) Dongmei Luo, Ye Liu, The Anatomy of Sports Injuries, First ed., Beijing Sport University Publishing, Beijing, 2013.

[3] (In Chinese) Anli Wang, Effective Functional Progressions in Sport Rehabilitation, First ed., Beijing Sport University Publishing, Beijing, 2011.

[4] Ronald T. Azuma, A Survey of Augmented Reality, J. Teleoperators and Virtual Environments. 6(1997)355-385.

[5] Luo X, Kenyon RV, Kline T, et al, An augmented reality training environment for post- stroke finger extension rehabilitation, C. Chicago, USA: Proceedings of the 9th International Conference on Rehabilitation Robotics. 2005, pp. 329-332.

[6] Irene Karaguilla Ficheman, Marilena do Nascimento, et al. Computer Assisted Music Therapy: a case Study of an Augmented Reality Musical System for Children with Cerebral Palsy Rehabilitation[C]. 2009 Ninth IEEE International Conference on Advanced Learning Technologies, 2009, pp. 218-220.

[7] Burke JW, McNeill MDJ, Charles DK. Augmented reality games for upper-limb stroke rehabilitation[C]. Washington D.C., USA: Proceedings of the Second International Conference on Games and Virtual Worlds for Serious Applications, 2010, pp. 75-78.

[8] Aung YM, Adel AJ. AR Based Upper Limb Rehabilitation System[C]. Roma, Italy: Proceedings of the 4th IEEE RAS\&EMBS International Conference on Biomedical Robotics and Biomechatronics, 2012, pp. 213-218.

[9] Hondori HM, Khademi M, Dodakian L. A spatial augmented reality rehab system for post-stroke hand rehabilitation, J. Stud Health Technol Inform, 184 (2013) 279-285.

[10] Gilda Aparecida de Assis, Roseli de Deus Lopes, et al. Perception of Health Professional about Clinical Utility of an Augmented Reality Musical System to Motor and Cognitive Rehabilitation[C]. 2014 XVI Symposium on Virtual and Augmented Reality, 2014, pp. 71-79.

[11] (In Chinese) Kun Wang. The Research of Training Rehabilitation System Based on Augmented Reality [D]. Southeast University, 2013.

[12] (In Chinese) Anning Chen. Medical sensors, Second ed., Science Publishing Ltd, Beijing, 2008.

[13] (In Chinese) Ming Liu, Research on Mobile Augmented Reality Tracking Technology and its Application in the Agricultural Exhibition[D], Southwest University, 2014.

[14] Liu C B, Chen C C, Li X. Object Tracking System in Dynamic Scene Based on Improved Camshift Algorithm and Kalman Filter[C]. Applied Mechanics and Materials. 602(2014): 2061-2064.

[15] Yiming Cai, Xiao Li. CrazyCartoon: the Design and Implementation of a User-defined Strategic 
Tower Defense System with MobileAR[C], First International Conference on Information Science and Electronic Technology, 2015, pp. 49-52. 